\title{
Thermal Analysis of High Speed Induction Motor by Using Lumped-Circuit Parameters
}

\author{
Pil-Wan Han*, Jae-Hak Choi*, Dong-Jun Kim*, Yon-Do Chun* and Deok-Je Bang ${ }^{\dagger}$ \\ Abstract - This paper deals with the electromagnetic and thermal analysis of high speed induction \\ motor. The induction motor is analyzed by time-varying magnetic finite element method and its \\ thermal analysis is carried out by using analytical lumped-circuit method. Analysis results are \\ compared with the experiment of $29 \mathrm{~kW}$ high speed motor prototype at $12,000 \mathrm{rpm}$.
}

Keywords: High speed, Induction motor, Thermal analysis, Lumped parameter

\section{Introduction}

The thermal analysis of electric machine has received less attention than electromagnetic analysis. Motor designers have only superficially dealt with the thermal design aspects by specifying a limiting value of current density or some other sizing variables. As it is impossible to accurately analyze one (electromagnetic) without the other (thermal), the losses are critically dependent upon the temperature and vice versa [1].

Electric motor thermal analysis can be divided into the following two basic types: analytical lumped-circuit and numerical methods. The analytical approach has the advantage of being very fast to calculate, but the developer of the circuit model must invest effort in defining a circuit that accurately models the main heat transfer paths [2-4].

The main strength of numerical analysis is that any device geometry can be modeled. However, it is very demanding in terms of model setup and computational time. There are two types of numerical analysis: the finite-element analysis (FEA) and the computational fluid dynamics (CFD) [5, 6].

In order to obtain an accurate thermal model for an electrical machine, both the analytical and numerical approaches benefit from the previous experience of the designer. This is due to some thermal phenomena being dependent upon the manufacturing process, such as the smoothness of the outer stator lamination and the inner housing surface [2].

In this paper, to analyze thermal characteristics of high speed induction motor of $29 \mathrm{~kW}-12,000 \mathrm{rpm}$, lumpedcircuit parameters thermal network method of commercial software is used [4]. The Induction motor of this study is driven by sinusoidal voltage without PWM inverter.

$\dagger$ Corresponding Author: Electric Motor Research Center, Korea Electrotechnology Research Institute, Korea.

* Electric Motor Research Center, Korea Electrotechnology Research Institute, Korea. (pwhan@keri.re.kr)

Received: January 15, 2015; Accepted: May 13, 2015

\section{Loss Analysis and Test of High Speed Motor}

\subsection{Specification of motor}

In the last decade increasing attention has been given to high-speed drives for wider range of application, such as compressors, turbochargers, blowers, flywheel energy storages and spindles for machine tool [2].

This paper studies 29kW-12,000rpm (Max. 60kW$25,000 \mathrm{rpm}$ ) high speed induction motor including water cooling jacket as shown in Table 1. Fig. 1 is torque and power characteristics of motor which could be used in a high speed spindle system.

Table 1. Specification of high speed motor

\begin{tabular}{c|c|c|c}
\hline Items & Unit & Rated & Maximum \\
\hline Power & $\mathrm{kW}$ & 29 & 60 \\
\hline Rated line voltage & $\mathrm{V}$ & 182 & 380 \\
\hline Rated frequency & $\mathrm{Hz}$ & 400 & 833 \\
\hline Rated speed & $\mathrm{RPM}$ & 12,000 & 25000 \\
\hline Cooling condition & \multicolumn{4}{|c}{ Water cooling $\left(7 \mathrm{~L} / \mathrm{min}, 20^{\circ} \mathrm{C}\right)$} \\
\hline
\end{tabular}

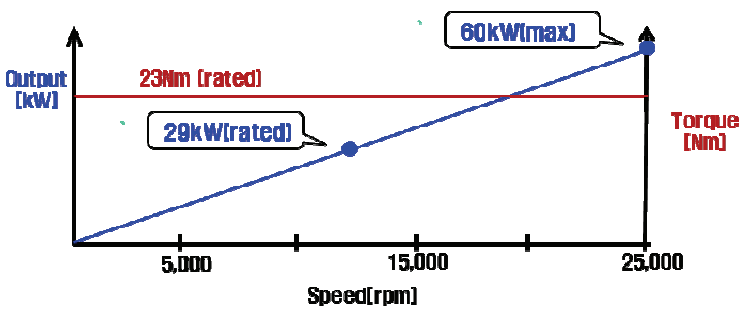

Fig. 1. Rated performance vs Speed

\subsection{Design of motor}

The high speed motor of this paper is designed as two types. First model is designed on high current density and it is expected to have bad thermal characteristics. In addition, this design has problems in centrifugal casting copper rotor due to small rotor slot. The second model is modified to make up for the first model's defects as show 


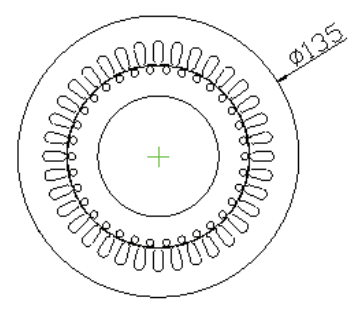

(a) $1^{\text {st }}$ model

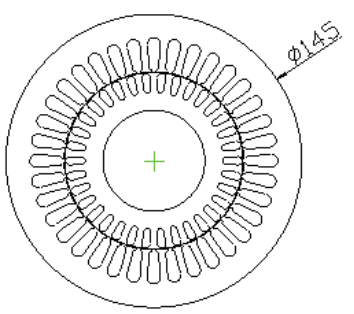

(b) $2^{\text {nd }}$ model
Fig. 2. Drawings of core.

Table 2. Design of High Speed Motor

\begin{tabular}{c|c|c|c}
\hline Items & Unit & $1_{\text {st }}$ & $2_{\text {nd }}$ \\
\hline Out diameter of stator & $\mathrm{mm}$ & 135 & 145 \\
\hline Inner diameter of stator & $\mathrm{mm}$ & 88 & 88 \\
\hline Stack length & $\mathrm{mm}$ & 150 & 150 \\
\hline Current density of stator & $\mathrm{A} / \mathrm{mm}^{2}$ & 18.0 & 8.44 \\
\hline Current density of rotor & $\mathrm{A} / \mathrm{mm}^{2}$ & 20.7 & 7.09 \\
\hline Flux density of airgap & $\mathrm{T}$ & 0.76 & 0.60 \\
\hline Electrical steel thickness & $\mathrm{mm}$ & 0.35 & 0.2 \\
\hline Core loss at $1.5 \mathrm{~T} / 834 \mathrm{hz}$ & {$[\mathrm{W} / \mathrm{kg}]$} & 139 & 139 \\
\hline Rotor conductor & \multicolumn{3}{|c}{ copper } \\
\hline
\end{tabular}

in Table 2 and Fig. 2. Area of stator and rotor slots is increased more than two times to reduce current and flux density and improves the productivity of centrifugal casting copper rotor.

\subsection{Loss analysis and test results}

The basic losses such as copper loss and iron loss are calculated by 2D electro-magnetic FEM using sinusoidal voltage.

The induction motor is analyzed by time-varying magnetic finite element analysis at rated condition $(182 \mathrm{~V} /$ $400 \mathrm{~Hz}$ ) by using sinusoidal voltage. Fig. 3 shows the flux density distribution of designed models ( $2^{\text {nd }}$ model). Maximum value of stator yoke and teeth flux density is 1.4 [T] and $1.6[\mathrm{~T}]$ respectively.

Table 3 shows the loss analysis by 2D FEM and test results in sinusoidal voltage. If this machine is driven by PWM inverter, its efficiency can decrease because of harmonic loss. A stator winding and rotor bar temperature

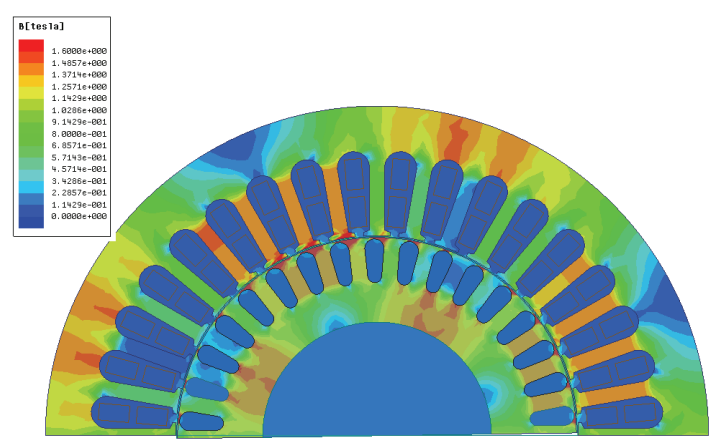

Fig. 3. Flux density distribution
Table 3. Comparison of loss analysis and test results

\begin{tabular}{c|c|c|c|c|c|c|c}
\hline \multirow{2}{*}{ Method } & Eff. & \multicolumn{6}{|c}{ Losses [W] } \\
\cline { 2 - 8 } & {$[\%]$} & Total & $\begin{array}{c}\text { Stator } \\
\text { copper }\end{array}$ & $\begin{array}{c}\text { Rotor } \\
\text { copper }\end{array}$ & Iron & Mech. & $\begin{array}{c}\text { Stray } \\
\text { load }\end{array}$ \\
\hline FEM & 92.6 & 2306 & 535 & 427 & 429 & 174 & 743 \\
\hline TEST & 91.9 & 2555 & 622 & 453 & 420 & 197 & 863 \\
\hline
\end{tabular}

are set on $80^{\circ} \mathrm{C}$ and $150{ }^{\circ} \mathrm{C}$. A stray load loss is calculated by about $2.5 \%$ of output power and a mechanical loss by using Takeuchi's formula [11].

Testing of prototype is done by IEC 60034-2-1, loss segregation method by means of output power.

\subsection{Prototype assembling process}

Fig. 4 shows a process assembling prototype. A rotor bar is made by centrifugal copper casting and stator is molded by a synthetic resin to improve cooling capacity.

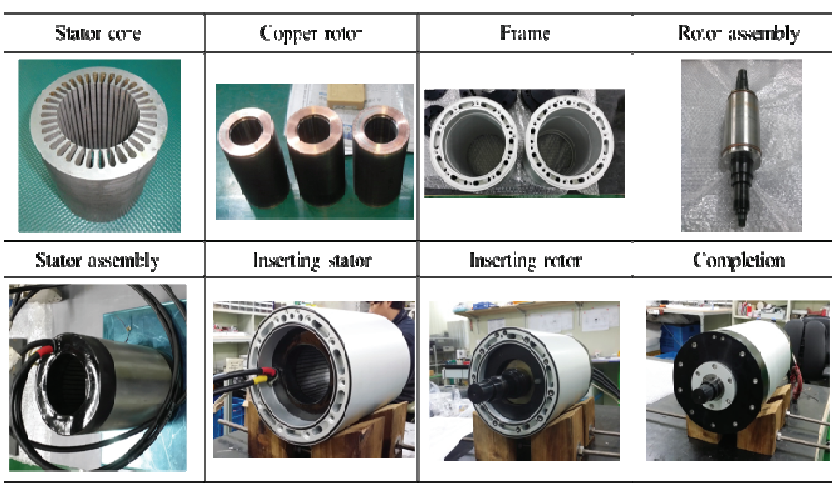

Fig. 4. Assembling prototype

\section{Parameter Calculations}

\subsection{Lumped parameter thermal network (LPTN) method}

LPTN method has been successfully used for thermal analysis of electric motors using commercial software as shown in [4]. All thermal parameters, such as conduction $\left(\mathrm{R}_{\mathrm{c}}\right)$, radiation $\left(\mathrm{R}_{\mathrm{r}}\right)$, convection thermal resistances $\left(\mathrm{R}_{\mathrm{cv}}\right)$ and flow resistance $\left(R_{f}\right)$ in case of forced convection heat transfer are calculated by program considering cooling system as shown in Eqs. (3) (6) [1].

$$
\begin{gathered}
R_{c}=\frac{L}{k A} \\
R_{r}=\frac{1}{h_{R} A} \\
R_{c v}=\frac{1}{h_{C} A}
\end{gathered}
$$




$$
R_{f}=\frac{k \rho}{2 A^{2}}
$$

where $\mathrm{L}$ is the path length, $\mathrm{A}$ is the path or surface area, $\mathrm{k}$ is the thermal conductivity, $h_{R}$ is heat-transfer coefficient, $\mathrm{h}_{\mathrm{C}}$ is the convection-heat-transfer coefficient and $\rho$ is the air or fluid density depending on the temperature.

\subsection{Analysis of forced convection (water jacket)}

In this study, high speed motor is cooled by water jacket as shown in Fig. 5. In a forced convection system, if the fluid velocity is large, the turbulence is induced. The magnitude of $R e$ (Reynolds number) of Eq. (7) is used to if there is laminar or turbulent flow in a forced convection system [8, 12, 15 17]. Re is calculated to 13,140 in this model. For fully developed turbulent flow $(3,000<R e<$ $\left.10^{6}\right), \mathrm{Nu}$ (Nusselt number) and heat transfer coefficient are calculated by Eq. (9) and (10) [13].

$$
\begin{gathered}
\operatorname{Re}=\rho \cdot v \cdot L / \mu \\
\operatorname{Pr}=c_{P} \cdot \mu / k \\
N u=\frac{f}{8} \cdot \frac{(\operatorname{Re}-1000) \cdot \operatorname{Pr}}{1+12.7 \cdot(f / 8)^{0.5} \cdot\left(\operatorname{Pr}^{2 / 3}-1\right)} \\
N u=\mathrm{h} \cdot L / k
\end{gathered}
$$

where $\operatorname{Pr}$ is Prandtl number, $v$ is fluid velocity $[\mathrm{m} / \mathrm{s}], \mathrm{c}_{\mathrm{p}}$ is fluid specific heat capacity $\left[\mathrm{kJ} /\left(\mathrm{kg} \cdot{ }^{\circ} \mathrm{C}\right)\right], \mu$ is fluid dynamic viscosity $[\mathrm{kg} / \mathrm{m} / \mathrm{s}]$, $\mathrm{f}$ is the friction factor [8].

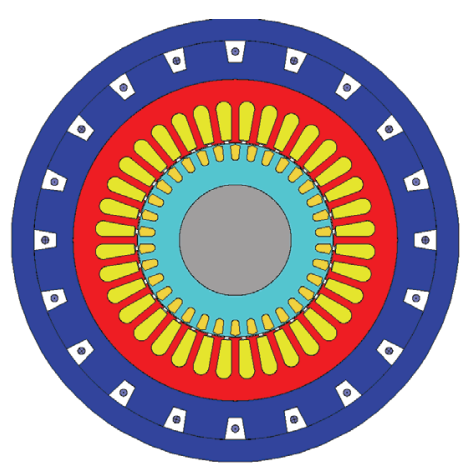

Fig. 5. Cross section of motor

\subsection{Analysis of forced convection (Air Gap)}

The traditional method to account for heat transfer across air gap is to use the dimensionless convection correlations developed from testing on smooth concentric rotating cylinders by Tayler $[8,14]$. In order to judge if the flow in the air gap is laminar, vortex or turbulent, the Taylor number $(T a)$ has to be calculated using Eq. (11). The flow is laminar if $T a<41$. If $41<T a<100$ (Our model: 79.5), the flow takes on a vertex form and Eq. (12) has to be used to calculate $N u$ [8].

$$
T a=\operatorname{Re} \cdot\left(l_{g} / R_{r}\right)^{0.5}
$$

where $l g$ is the air gap radial thickness, $R r$ is the rotor outer radius, and $R e=l_{\mathrm{g}} \cdot v / \mu$

$$
N u=0.202 \cdot(T a)^{0.63} \cdot(P r)^{0.27}
$$

\subsection{Critical parameters}

The accuracy of thermal networks is dependent upon several parameters for which reliable data may be difficult to find, for example, the interface gap between components and thermal conductivity data of important materials used in electrical motors [2]. It is difficult to find appropriate thermal data of electrical steel, insulation and impregnation materials. Table 4 shows the thermal conductivity of these materials used in this thermal analysis. It is assumed that electrical steel contains silicon by $1.5 \%$ because its value is not released exactly by manufacturer.

Table 4. Thermal conductivity of important materials

\begin{tabular}{c|c|c}
\hline Material & $\begin{array}{c}\text { Thermal Conductivity } \\
{\left[\mathrm{W} / \mathrm{m} /{ }^{\circ} \mathrm{C}\right]}\end{array}$ & Remarks \\
\hline Electrical steel & 33 & Silicon $1.5 \%$ \\
\hline Epoxy & 1.02 & Molding of windings \\
\hline Nomex 410 & 0.14 & Slot liner \\
\hline Aluminum & 168 & Housing \\
\hline
\end{tabular}

The accuracy of a motors thermal performance prediction is also dependent upon the estimate of the many thermal contact resistances within the machine (stator lamination to housing, slot-liner to lamination, etc) [9]. The data given by Mills [10] can be converted to equivalent air gaps by using a thermal conductivity for air of $0.026 \mathrm{~W} / \mathrm{m} / \mathrm{C}$. For the typical material interfaces found in electrical machines, values of an interface gap for aluminum - aluminum are in the range 0.0005 to $0.0025 \mathrm{~mm}$ and aluminum - iron of 0.0006 to $0.006 \mathrm{~mm}$ [10]. The gap between lamination and housing is a function of how well the rough laminated outer surface of the stator is prepared before the housing is fitted. This study used $0.01 \mathrm{~mm}$ as the gap between lamination and aluminum housing considering the roughness of lamination.

\section{Thermal analysis and test results}

\subsection{Parameters for thermal analysis}

Table 5 and Fig. 6 show the heat transfer coefficients of important parts and thermal resistances by commercial software using theory of chapter 3 .

In this study, as the high speed motor is water cooling type, heat transfer coefficients of water jacket channel and interface between stator core and frame are dominant. 


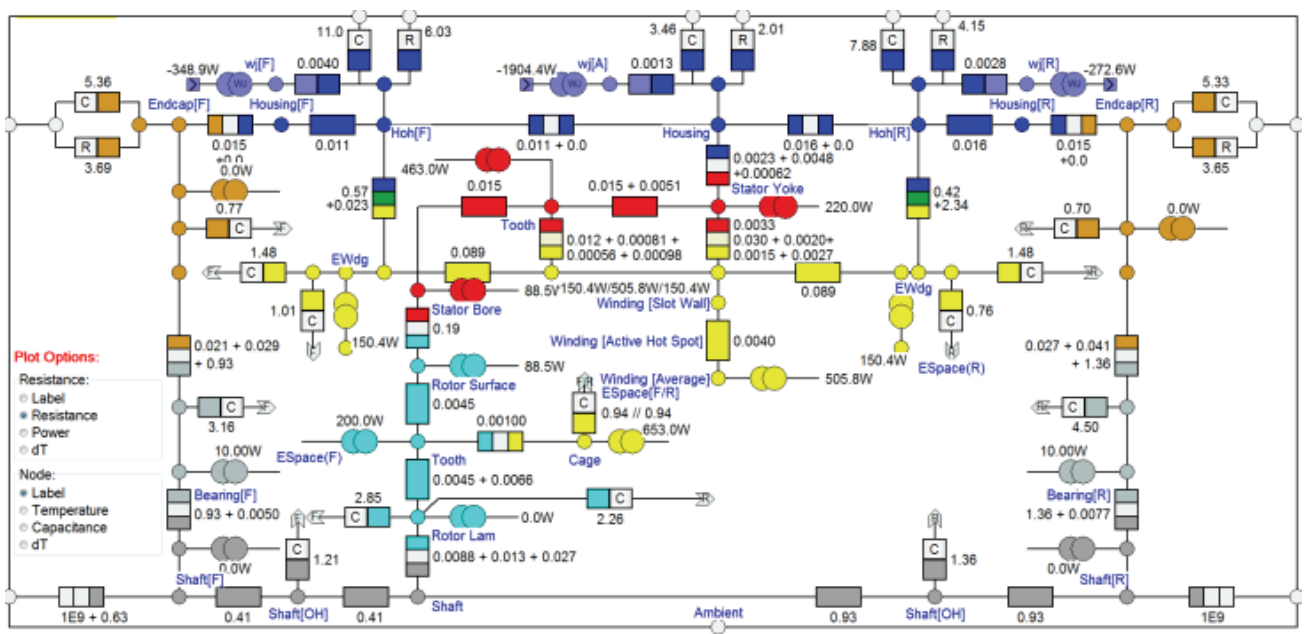

Fig. 6. Thermal equivalent circuit (resistances)

Table 5. Heat transfer coefficient of important parts

\begin{tabular}{c|c|c}
\hline Components & $\begin{array}{c}\text { Heat tran. coef. } \\
{\left[\mathrm{W} / \mathrm{m}^{2} /{ }^{\circ} \mathrm{C}\right]}\end{array}$ & Remarks \\
\hline Air gap & 128.1 & Convection \\
\hline Water jacket channel & 6,997 & Convection \\
\hline From end coil to inner air & 133 & Convection \\
\hline From end ring to inner air & 210 & Convection \\
\hline From housing to outer air & 8.3 & Conv.+Rad. \\
\hline Between stator core and Frame & 2,600 & Interface gap \\
\hline
\end{tabular}

\subsection{Analysis results and comparison with test results}

Fig. 7 is temperature distribution as the thermal analysis results by LPTN method. The details of analysis results are shown in Table 6 which shows analysis results by using loss analysis and test results of chapter 2. Test results of motor temperature are from temperature saturation test of Fig. 8 by using 60kW Dynamo system as shown in Fig. 9.

The difference between stator and rotor temperature is high over $100^{\circ} \mathrm{C}$ because this model is housing water cooling type (cooling water condition in Table 1). Thermal analysis results using FEM losses are lower than test losses due to lower FEM losses than test losses.

A temperature of rear part of end winding is higher than that of front part because rear part has a little gap with housing as shown in Fig. 5 in assembling process

If the interface gap between housing and lamination or equivalent thermal conductivity between winding and lamination are adjusted, winding temperature in slot can be calculated accurately.

Table 6. Temperature distribution by thermal analysis

\begin{tabular}{c|c|c|c|c|c|c}
\hline \multirow{2}{*}{ Method } & \multicolumn{3}{|c|}{ Winding $\left[{ }^{\circ} \mathrm{C}\right]$} & \multicolumn{2}{c|}{ Rotor[ $\left.{ }^{\circ} \mathrm{C}\right]$} & \multirow{2}{*}{ Remarks } \\
\cline { 2 - 6 } & $\begin{array}{c}\text { End part } \\
\text { (front) }\end{array}$ & In slot & $\begin{array}{c}\text { End part } \\
\text { (rear) }\end{array}$ & core & shaft & \\
\hline Analysis & 71.3 & 66.5 & 76.3 & 172.3 & 166 & $\begin{array}{c}\text { By FEM } \\
\text { losses }\end{array}$ \\
\hline Analysis & 77.7 & 72.2 & 83.3 & 185.3 & 179 & $\begin{array}{c}\text { By test } \\
\text { losses }\end{array}$ \\
\hline Test & 75.2 & 65.5 & 80.4 & - & - & \\
\hline
\end{tabular}

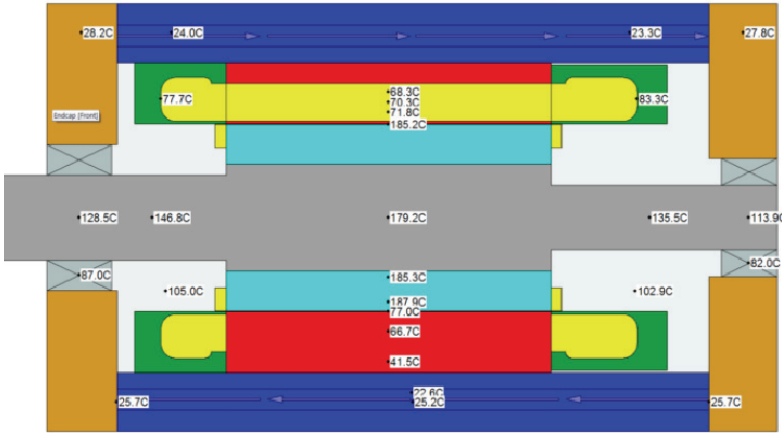

Fig. 7. Temperature distribution (Test losses)

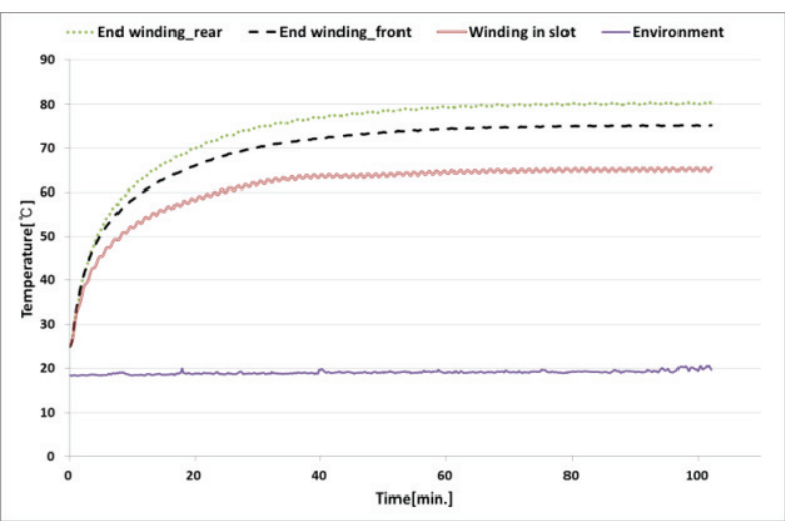

Fig. 8. Temperature saturation test

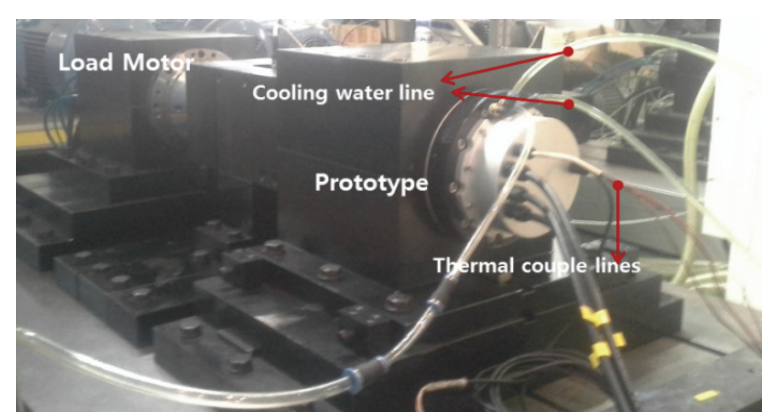

Fig. 9. Dynamo system for testing 


\section{Conclusion}

This paper has presented the thermal analysis of water cooling type high speed induction motor by using analytical lumped-circuit method shown in [4]. If critical parameters such as interface gap between materials and thermal conductivity of important materials are selected well considering manufacturing conditions, a temperature of motor can be expected accurately in LPTN method. In motor design step, loss analysis results are also important factors to analyze temperature characteristics.

\section{Acknowledgment}

This work was supported by the the Energy Efficiency \&Resources of the Korea Institute of Energy Technology Evaluation and Planning (KETEP) grant funded by the Korea government Ministry of Trade, Industry, \& Energy (No. 20122010100070).

\section{References}

[1] A. Boglietti, A. Cavagnino and D. Staton, "Evolution and Modern Approaches for Thermal Methods Analysis of Electrical Machines", IEEE Trans. on Industrial Elec., vol. 56, no. 3, pp. 249-255, Jan./Feb., 2010.

[2] A. Boglietti, A. Cavagnino and D. Staton, "Determination of Critical Parameters in Electrical Machine Thermal Models", IEEE Trans. on Industry App., vol. 44, no. 4, pp. 1150-1159, Jul./Aug., 2008.

[3] P. Mellor, D. Roberts, and D. Turner, "Lumped parameter thermal model for electrical machines of TEFC design", Proc. Inst. Elec. Eng., vol. 138, no. 5, pp. 205-219, Sep. 1991.

[4] Motor-CAD. [Online]. Available: www.motor-design. com

[5] D. Staton, S. J. Pickering, and D. Lampard, "Recent advancement in the thermal design of electric motors," in Proc. SMMA Fall Tech. Conf., Durham, NC, Oct. 3-5, 2001, pp. 1-11.

[6] D. Staton, "Thermal analysis of electric motors and generators," presented at the IEEE IAS Annual Meeting, Chicago, IL, 2001.

[7] A. Boglietti, A. Cavagnino, and D. Staton, "TEFC induction thermal models: A parameters sensitivity analysis," IEEE Trans. Ind. Appl., vol. 41, no. 3, pp. 756-763, May/Jun. 2005.

[8] D. A. Staton and A. Cavagnino, "Convection heat transfer and flow calculations suitable for electric machines thermal models", IEEE Trans. on Industrial Elec., vol. 55, no. 10, pp. 3509-3516, Oct., 2008.

[9] D. Staton, A. Boglietti and A. Cavagnino, "Solving the More Difficult Aspects of Electric Motor Thermal Analysis in Small and Medium Size Industrial In- duction Motors", IEEE Trans. on Energy Con., vol. 20, no. 3, pp.620-628, Sept., 2005.

[10] A. F. Mills, Heat Transfer. Englewood Cliffs, NJ: Prentice Hall, 1999.

[11] T. Takeuchi, Electric Machine design, Ohmsha, 1979.

[12] D. W. Van De Pol and J. K. Tierney, "Free convection Nusselt number for vertical U-shaped channels," Trans. ASME, vol. 95, pp. 542-543, Nov. 1973.

[13] V. Gnielinski, "New equations for heat and mass transfer in turbulent pipe and channel flow," Int. Chem. Eng., vol. 16, pp. 359-368, 1976.

[14] G. I. Taylor, "Distribution of velocity and temperature between concentric cylinders," Proc. Roy Soc., vol. 159, pp. 546-578, 1935.

[15] A. F. Mills, Heat Transfer. Englewood Cliffs, NJ: Prentice-Hall, 1999.

[16] C. D. Jones and L. F. Smith, “Optimum arrangement of rectangular fins on horizontal surfaces for freeconvection heat transfer," Trans. ASME, vol. 92, pp. 6-10, Feb. 1970.

[17] F. Heiles, "Design and arrangement of cooling fins," Elecktrotecknik und Maschinenbay, vol. 69, no. 14, pp. 42-48, Jul. 1952.

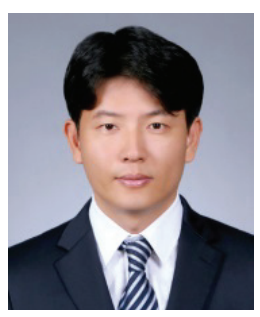

Pil-Wan Han He received the B.S., M.S. and Ph.D. degrees in Electrical Engineering from Hanyang University in 1998, 2000 and 2013 respectively. From 2000 to 2005 , he worked at LG electronics. Since 2005, he has worked at Korea Electrotechnology Research Institute (KERI). He is currently a senior researcher of Electric Motor Research Center, KERI.

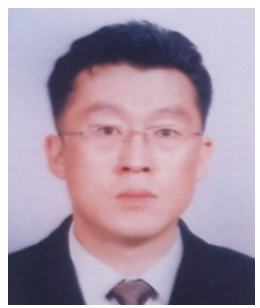

Jae-Hak Choi He received the B.S., M.S., and Ph.D. degrees in Electrical Engineering from Hanyang University in 1999, 2001 and 2005 respectively. From 2005 to 2007, he worked at LG electronics. Since 2008, he has worked at Korea Electrotechnology Research Institute (KERI). He is currently a senior researcher of Electric Motor Research Center, KERI.

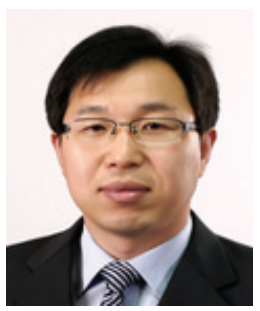

Dong-Jun Kim He received B.S degree in electrical engineering in 2004 from Kyungnam University. He received M.S degree in electrical engineering in 2013 from Changwon National University. He has worked at Korea Electrotechnology Research Institute (KERI). He is currently a senior Engineer of Electric Motor Research Center, KERI. 


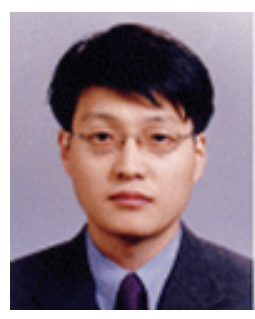

Yon-Do Chun $\mathrm{He}$ received the B.S., M.S. and Ph.D. degrees in electrical Engineering from Hanyang University in 1996, 1998 and 2001, respectively. From 2001 to 2003, he received a Japan Society for the Promotion of Science (JSPS) fellowship and he was with the Department of Electrical Engineering at Waseda University as a visiting scholar. From 2004 to 2012, he has worked at Korea Electrotechnology Research Institute (KERI). He is currently a chief researcher, Principal Researcher and technical leader of Electric Motor Research Center, KERI.

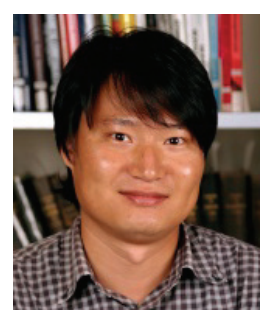

Deok-je Bang He received the B.Sc. and M.Sc. degrees in mechanical engineering from Pukyong National University, Busan, South Korea in 1996 and 1998, respectively. He received the $\mathrm{Ph} . \mathrm{D}$. degree in electrical engineering from Delft University of Technology in The Netherlands in 2010. From 1998 to 2006 , he worked in the research area of electrical machines and automatic transportation systems. In 2011, he was a principal researcher and a team leader at Wind Turbine Research Division, Hyundai Heavy Industries. Since 2012, he has been working as a team leader of Large Wind Generator System Research Team at Electric Motor Research Center, Korea Electrotechnology Research Institute in South Korea. His research interests include direct-drive generators for wind and ocean energy conversion systems. 